\title{
PREVALENCE OF OVERWEIGHT AND OBESITY IN 2-5 YEARS CHILDREN BASED ON NEW WHO GROWTH STANDARDS IN AHWAZ, IRAN
}

\author{
S. Nouhjah ${ }^{1}$, M. Karandish ${ }^{2}$, R. Malihi ${ }^{3}$, F. Tamadon ${ }^{4}$ \\ ${ }^{\text {I}}$ Public Health, Joundishapour Medical Sciences University, Ahvaz, ${ }^{2}$ Diabetes Research Center, Department \\ of Nutrition, School of Paramedical, ${ }^{3}$ Department of Nutrition, ${ }^{4}$ Public Health, Medical Sciences University \\ of Jondishapour, Ahwaz, Iran
}

Background: Child hood obesity is a potentially risk factor for many health consequences, both in the short term and for their adult life. Few data of children obesity prevalence based on new WHO growth standards exist in Iran.

Method: In cross-sectional study 1035 children 2-5 years old attending 18 public health centers for routine health care were surveyed in 2009. Interview with mother, filling a questionnaire by trained questioner and measurement of weight and height by trained investigators were instruments for data collection. Soft ware of WHO for PL ( WHO anthro version3 2006) used for data analysis after entrancing data in SPSS software. $\mathrm{BMI} /$ age above $2 \mathrm{SD}$ of median).

Results: Overall prevalence of overweight was $15 \%$. This prevalence were $19.4 \%, 12.6 \%$ and $12.4 \%$ in age group 24-35,36-47,48-60 months respectively. $16.7 \%$ of boys and $13.3 \%$ of girls Overall, $15 \%$ of the children studied were overweight. Highest prevalence of overweight was observed in the 35-24 month age group (19.4\%). In different age groups of boys and girls, the prevalence of overweight was calculated $16.7 \%$ and $13.3 \%$ respectively. Overall prevalence of obesity was $7.3 \%$. Highest prevalence of obesity in the $35-24$ month age group (10.4\%) was observed. Prevalence of obesity in boys and girls was 9\% and 5.6\% respectively.

Conclusion: Risk of overweight in children has reached alarming proportion in Ahwaz. Urgent public health strategies are needed to prevent childhood obesity. 